\title{
Experimental Investigation of Dimensional Accuracy in Non-traditional Sheet Metal Spinning Process for Producing Rectangular Spun Part
}

\author{
Ammar M. Saleh*, Aseel H. Abd, Aqeel S. Bedan \\ Production engineering and Metallurgy Department, University of Technology, Baghdad, Iraq. \\ *Corresponding author Email: 70168@uotechnology.edu.iq
}

\section{H I G H L I G H T S}

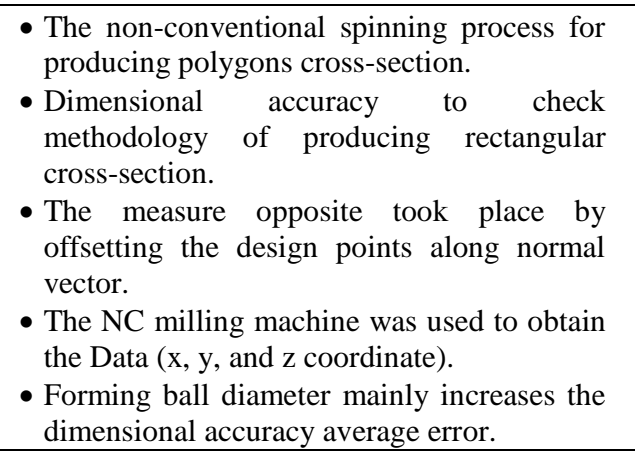

\section{A R T I C L E I N F O}

\section{Handling editor: Muhsin J. Jweeg}

Keywords:

Ball diameter of forming tool

Dimensional accuracy

Feed ratio

Forming

Spindle speed

Non-conventional spinning process

\begin{abstract}
A B S T R A C T
The non-conventional spinning process was adopted for producing polygons, but one of the process limitations is the error between design and the final product especially with no-mandrel. Dimensional accuracy was adopted for this purpose which gives an indicator of the ability of the formed part to matches the design and checking validated of the adopted methodology for producing rectangular cross-section spun parts, by comparing the coordinating points of real part with the points of the design model. The point of a real part was measured by using a sphere probe fixed on the three-axis milling machine and capturing the data of machine axis movements for the center location of the probe, also, the measurements oppositely took place, by offsetting the points of design along the normal vector for comparison with the real part points. Three parameters were invested for study the effects on the dimensional accuracy, these parameters are spindle speed (48, 68, and $135 \mathrm{RPM})$, feed ratio $(0.16,0.22$, and $0.32 \mathrm{~mm} / \mathrm{rev})$, and the ball diameter of the forming tool $(16,22$ and $25 \mathrm{~mm})$. The results show that tool ball diameter mainly affecting dimensional accuracy with a higher value of average error reach $(6.47 \mathrm{~mm})$ when $16 \mathrm{~mm}$ diameter of tool ball was used, on the other hand, the minimum average error was $1.705 \mathrm{~mm}$ at low spindle speed.
\end{abstract}

\section{Introduction}

Generally spinning of sheet metal is known as a process that transforms circular flat metal blank sheet into an axisymmetric, hollow shapes part by using a forming tool that forces a blank onto a mandrel. On the other hand, the traditional spinning process limited to produces axisymmetric components [1]. But in the last 3 Decades, researchers were attempted to overcome this limitation by producing more complex parts such as the researcher, Zhen Jia et al (2014) [2], presented an Investigation of the spinning process to expose the mandrel-less spinning technique to produce the square section spun part. Furthermore, exposed development of modulation of finite elements accompanied by the formation of a roller path as a boundary condition and verified the accuracy of this modulation through several experiments [1]. Also, Yoshihiko Sugitaa et al (2014) [3], presented an experiment to form non-conventional forms by using a circular cone and transformed it to rectangular polygon. Where the cone was created by synchronous multi-pass spinning accompanied by rotational pass sets. In the cone forming the wrinkling occurred when the angle increases largely. On the other hand, the rectangular polygon was formed using rotational pass sets, folds appeared identical to the folds in conical types [2], furthermore Jacopo M. Russo et al (2020) [4], presented an investigation for manufacturing a non-conventional spun part using an adaptive new conceptual design machine, were attempted to produce a square and the form of a bean cross-section cup. Where In the beginning, a suitable design of blanks was achieved for such geometry, and showed that possible to eliminate the mandrel, and thus decreases costs, lead times, and materials substantially. Also, showed the methodology description for blanks development and tool paths, 
furthermore exhibits the results of the physical experimental for that adoptive machine [3], also, Zhen Jia et al (2020) [5], presented an investigation of the roller path in mandrel-less spinning forming technique to fulfill a circular square section spun parts by using a 5-axis CNC machine of the spinning process, where a roller path was designed, and adjusted to calculate the degree of the square section edge parts. The methodology used to make this square section required the roller to move in the radial direction forward and backward linked with a rotation of the blank and progressing in the $\mathrm{x}$-axis directions simultaneously, finally M. Razumov et al (2016) [6], presented a mathematical relationship proposal to calculate the shape of errors that happen through turning the polygons with an odd number of faces. The calculations were found that the real polygon profile differs from the real profile due to machining errors during the production of polygons with an odd number of faces. .

Finally, this study aims to check the validity of the non-conventional spinning of sheet metal process that adopted for producing the square section spun parts.

\section{Theoretical considerations}

The dimensional accuracy error can be well-defined as the distance error between the theoretical and experimental points on the surface in the spun part, where there is a distance error between the new geometry of the spun part and the design shape of the spun part assigned to the nature of the process [7].

The methodology was applied by calculating the contact location points of the designed surface by using Siemens NX software version 10, then transform these data to center location points by exporting that's data to Matlab Software version 2015 then calculate the normal vectors and then offset the data points along that's normal [8], finally import data by NX 10 Software from Matlab Software and change these points to surface by fitting operation which considers the reference surface for all measurement for the specific spun part [9], and comparing the measured surface were constructed by fitting the measured points by using NX10 Software also, on the other hands this methodology considers the opposite way for measuring error where the measure data don't transition along normal vector to become contact points because these data already have an error, also, consider the best way for accurate measuring especially when absence of the CMM machine. Figure (1) shows the steps that is used to measure the error between the design part and the manufactured part for rectangular shape.

\section{Experimental setup}

The geometrical errors that occur in the formed part are indicated of dimensional accuracy of the parts made by that forming process. The NC milling machine positioned in the University of Technology/Production and Metallurgy Engineering Dept./ metal cutting laboratory was used to obtain the experimental Data ( $\mathrm{x}, \mathrm{y}$ and $\mathrm{z}$ coordinate), by using a probe with a spherical head (diameter $10.3 \mathrm{~mm}$ ) and multimeter on buzzer position (when probe contact surface of the spun part give indicator light with sound), then register the displayed $\mathrm{x}, \mathrm{y}$, and $\mathrm{z}$ coordinate that's appeared on the NC machine screen, the data obtained by this method represent the center location of the probe. Figure (2) shows the measurement method by using the NC machine, probe, and multimeter.
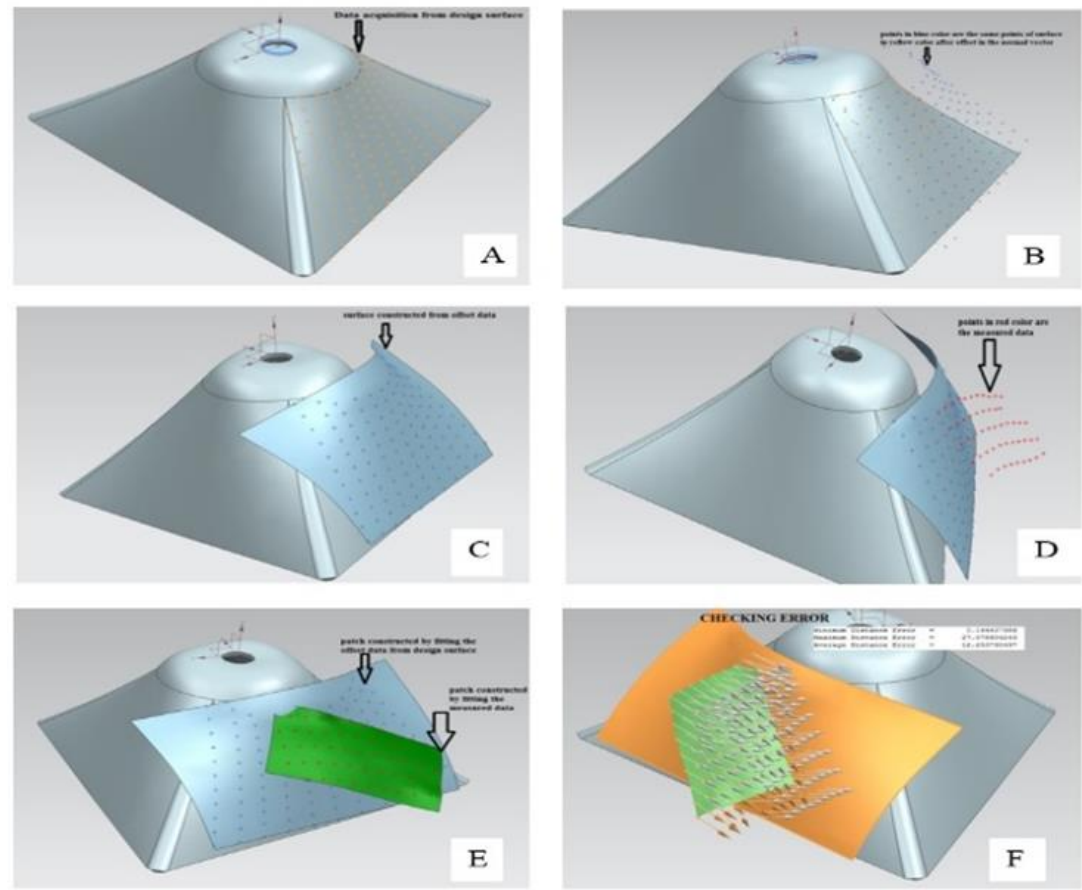

Figure 1: The steps that used to measure the error between design part and manufactured part for rectangular shape as example, where : (A) data acquisition, (B) data offset along normal, (C) surface by fitting data, (D) measured data points, (E) surface fit from measured data, (F) illustration the measured error. 


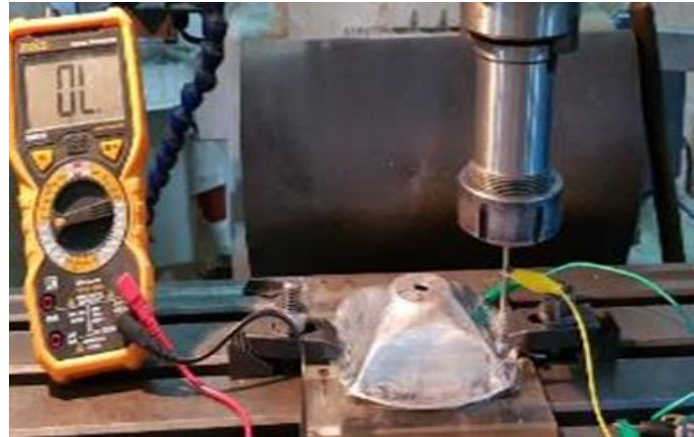

(A)

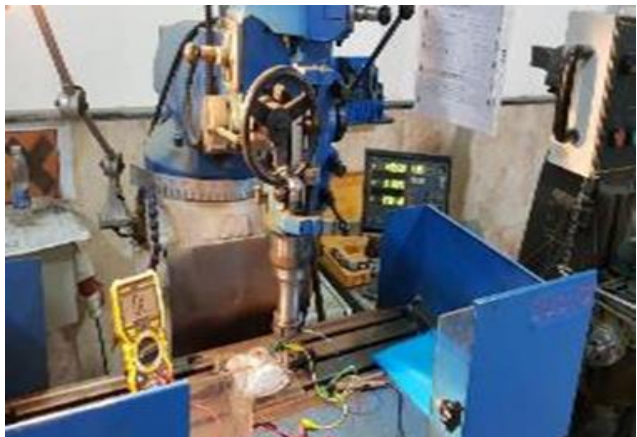

(B)

Figure 2: The measurement method, where: (A) focus on the probe, part and multimeter, while (B) displays the whole $\mathrm{NC}$ machine.

\section{Dimensional accuracy error comparison analysis for rectangular spun parts}

The comparison has been done between the two patches by using Siemens NX 10 software, also, the analysis data from the comparison where the number of the points checked was 104 points depends on the 12 points in both $\mathrm{U}$ and $\mathrm{V}$ patch direction and the distance with angular tolerance were chosen to be $5 \mathrm{~mm}$ for all the checked parts depends on the nature of spinning process especially when the absence of the supports or mandrel part. Figure (3) shows the comparisons for all parts.

\section{Results and discussion}

The results were illustrated in Tables from Table I to the Table IX for sample 1 to sample 9.

- From Table $\mathrm{X}$ it is clear that the tool ball diameter mainly effecting on dimensional accuracy with a higher value of average error in dimensional accuracy reached (6.47) in sample 8 where the error analysis for sample 8 was shown in the Table VIII. This way give better indicator than result depending on shape error as mentioned by $\mathrm{M}$. Razumov et al (2016) [6].

- Table VIII elucidated that the number of points lie outside tolerance was 87 point from 101 point which consider a high error value or part was fail when $16 \mathrm{~mm}$ diameter of tool ball was used, as shown in figure (3) for the same sample 8 .

- The minimum error in average dimension was 1.705 as shown in Table II for sample 2 which formed under spindle speed $48 \mathrm{RPM}$, feed ratio $0.22 \mathrm{~mm} / \mathrm{rev}$, and tool ball diameter $22 \mathrm{~mm}$, due to the low spindle speed, which coincide with the result by Jacopo M. Russo et al (2020) [4] .
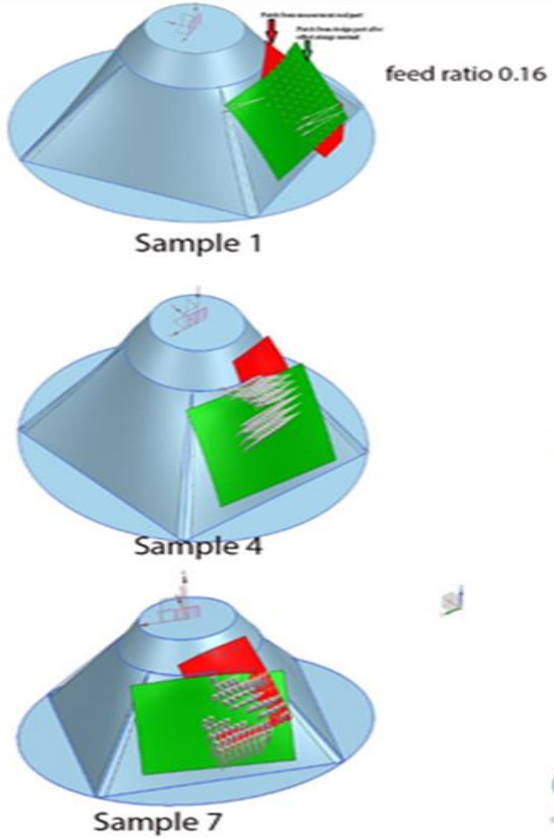

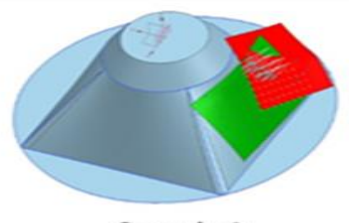

Sample 2

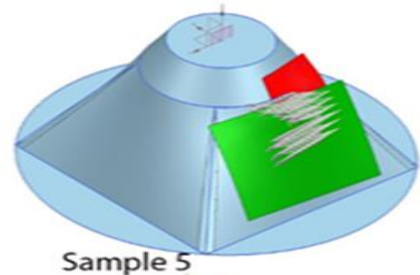

y

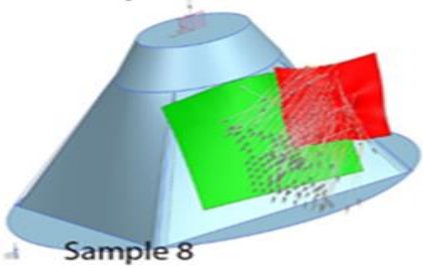

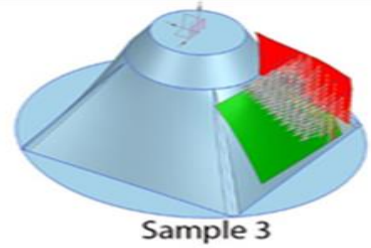

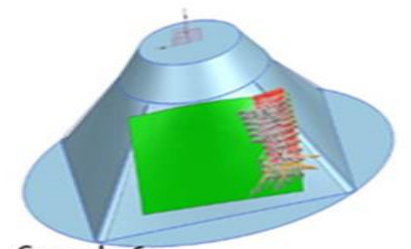

Sample 6

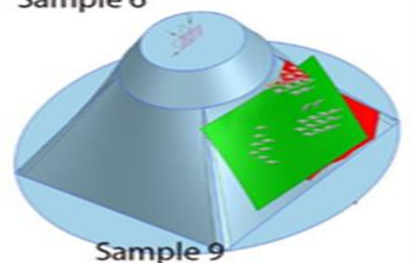

Figure 3: The design of rectangular parts with two patches, the red one represents the fitting measurement data from real rectangular part, and the red patch represents the data points acquisition from design part where offsets along normal vector, finally arrows represent the points at out of tolerance. 
Table 1: The dimensional accuracy error analysis for rectangular spun parts (Sample 1) by Ss 48RPM, feed ratio $0.16 \mathrm{~mm} / \mathrm{rev}$,

\begin{tabular}{c|ccc}
\hline SAMPLE 1 & \multicolumn{2}{c}{ Distance Error } \\
\hline Number of Points Checked & \multicolumn{2}{c}{104} & \\
Tolerance & \multicolumn{2}{c}{5} & $\mathrm{~mm}$ \\
Number Over desired Tolerance & \multicolumn{2}{c}{0} & \\
Minimum Error & 1.637 & $\mathrm{~mm}$ \\
Maximum Error & 4.145 & $\mathrm{~mm}$ \\
Average Error & 2.79 & $\mathrm{~mm}$ \\
\hline
\end{tabular}

and tool ball diameter $16 \mathrm{~mm}$.

Table 2: The dimensional accuracy error analysis for rectangular spun parts (Sample 2) by Ss 48 RPM, feed ratio $0.22 \mathrm{~mm} / \mathrm{rev}$, and tool ball diameter $22 \mathrm{~mm}$.

\begin{tabular}{c|ccc}
\hline SAMPLE 2 & \multicolumn{3}{c}{ Distance Error } \\
\hline Number of Points Checked & \multicolumn{2}{c}{75} & \\
Tolerance & 5 & $\mathrm{~mm}$ \\
Number Over desired Tolerance & \multicolumn{2}{c}{0} & \\
Minimum Error & 0.007 & $\mathrm{~mm}$ \\
Maximum Error & 4.113 & $\mathrm{~mm}$ \\
Average Error & 1.705 & $\mathrm{~mm}$ \\
\hline
\end{tabular}

Table 3: The dimensional accuracy error analysis for rectangular spun parts (Sample 3) Ss 48 RPM, feed ratio $0.32 \mathrm{~mm} / \mathrm{rev}$, and tool ball diameter $25 \mathrm{~mm}$.

\begin{tabular}{c|ccc}
\hline SAMPLE 3 & \multicolumn{2}{c}{ Distance Error } \\
\hline Number of Points Checked & \multicolumn{2}{c}{79} & \\
Tolerance & \multicolumn{2}{c}{5} & $\mathrm{~mm}$ \\
Number Over desired Tolerance & \multicolumn{2}{c}{49} & \\
Minimum Error & 0.37444 & $\mathrm{~mm}$ \\
Maximum Error & 11.6947 & $\mathrm{~mm}$ \\
Average Error & 5.84717 & $\mathrm{~mm}$ \\
\hline
\end{tabular}

Table 4: The dimensional accuracy error analysis for rectangular spun parts (Sample 4) Ss $68 \mathrm{RPM}$, feed ratio $0.16 \mathrm{~mm} / \mathrm{rev}$, and tool ball diameter $22 \mathrm{~mm}$.

\begin{tabular}{c|cc}
\hline SAMPLE 4 & \multicolumn{2}{c}{ Distance Error } \\
\hline Number of Points Checked & \multicolumn{2}{c}{83} \\
Tolerance & \multicolumn{2}{c}{$\mathrm{mm}$} \\
Number Over desired Tolerance & \multicolumn{2}{|c}{21} \\
Minimum Error & 0.7616 & $\mathrm{~mm}$ \\
Maximum Error & 5.92 & $\mathrm{~mm}$ \\
Average Error & 3.862 & $\mathrm{~mm}$ \\
\hline
\end{tabular}


Table 5: The dimensional accuracy error analysis for rectangular spun parts (Sample 5) Ss $68 \mathrm{RPM}$, feed ratio $0.22 \mathrm{~mm} / \mathrm{rev}$, and tool ball diameter $25 \mathrm{~mm}$

\begin{tabular}{c|c}
\hline SAMPLE 5 & Distance Error \\
\hline Number of Points Checked & 114 \\
Tolerance & $5 \mathrm{~mm}$ \\
Number Over desired Tolerance & 2 \\
Minimum Error & $1.225 \mathrm{~mm}$ \\
Maximum Error & $5.14 \mathrm{~mm}$ \\
Average Error & $2.9 \mathrm{~mm}$ \\
\hline
\end{tabular}

Table 6: The dimensional accuracy error analysis for rectangular spun parts (Sample 6) Ss 68 RPM, feed ratio $0.22 \mathrm{~mm} / \mathrm{rev}$, and tool ball diameter $16 \mathrm{~mm}$.

\begin{tabular}{c|c}
\hline SAMPLE 6 & Distance Error \\
\hline Number of Points Checked & \multicolumn{2}{c}{144} \\
Tolerance & $5 \quad \mathrm{~mm}$ \\
Number Over desired Tolerance & 100 \\
Minimum Error & $3.082 \mathrm{~mm}$ \\
Maximum Error & $9.0427 \mathrm{~mm}$ \\
Average Error & $5.844 \mathrm{~mm}$ \\
\hline
\end{tabular}

Table 7: The dimensional accuracy error analysis for rectangular spun parts (Sample 7) Ss 135 RPM, feed ratio $0.16 \mathrm{~mm} / \mathrm{rev}$, and tool ball diameter $25 \mathrm{~mm}$.

\begin{tabular}{c|c}
\hline SAMPLE 7 & Distance Error \\
\hline Number of Points Checked & 97 \\
Tolerance & $5 \mathrm{~mm}$ \\
Number Over desired Tolerance & 0 \\
Minimum Error & $0.0049 \mathrm{~mm}$ \\
Maximum Error & $4.52 \mathrm{~mm}$ \\
Average Error & $1.868 \mathrm{~mm}$ \\
\hline
\end{tabular}

Table 8: The dimensional accuracy error analysis for rectangular spun parts (Sample 8) by Ss $135 \mathrm{RPM}$, feed ratio $0.22 \mathrm{~mm} / \mathrm{rev}$, and tool ball diameter $16 \mathrm{~mm}$.

\begin{tabular}{c|c}
\hline SAMPLE 8 & Distance Error \\
\hline Number of Points Checked & 101 \\
Tolerance & $5 \mathrm{~mm}$ \\
Number Over desired Tolerance & 87 \\
Minimum Error & $3.932 \mathrm{~mm}$ \\
Maximum Error & $11.109 \mathrm{~mm}$ \\
Average Error & $6.470 \mathrm{~mm}$ \\
\hline
\end{tabular}


Table 9: The dimensional accuracy error analysis for rectangular spun parts (Sample 7) by Ss $135 \mathrm{RPM}$, feed ratio $0.32 \mathrm{~mm} / \mathrm{rev}$, and tool ball diameter $22 \mathrm{~mm}$.

\begin{tabular}{c|c}
\hline SAMPLE 9 & DISTANCE ERROR \\
\hline Number Of Points Checked & 92 \\
Tolerance & $5 \mathrm{~mm}$ \\
Number Over Desired Tolerance & 0 \\
Minimum Error & $0.007 \mathrm{~mm}$ \\
Maximum Error & $4.745 \mathrm{~mm}$ \\
Average Error & $2.244 \mathrm{~mm}$ \\
\hline
\end{tabular}

\section{Analysis of Variance}

Figure (4) shows the schematic illustration of the main effect of parameters on the average error. Also, Tables (X) shows the percentage effect of each parameter on the dimensional error, of the rectangular spun part

\section{Conclusions}

1) The results manifested that the maximum average of error in dimensional accuracy is $6.47 \%$, for rectangular spun parts, where were observed the big effect parameter was the diameter of the ball tool, where the effect percentage reach $32.43 \%$, for rectangular spun parts.

2) It was noticed that the minimum average error in dimensional accuracy is about 1.705 at spindle speed 48 RPM, feed ratio $0.22 \mathrm{~mm} / \mathrm{rev}$ and ball diameter of forming tool was $22 \mathrm{~mm}$.

3) Also , It was noticed that the feed ratio occupies the second order after tool ball diameter that effecting on the dimensional accuracy where the effect percentage reach $17.58 \%$ where the error reaches $5.84717 \mathrm{~mm}$ in sample 2 .

4) It was observed that the spindle speed has a very low effect on dimensional accuracy, where at 135 RPM the minimum error in dimensional accuracy reached to $1.868 \mathrm{~mm}$ and for $48 \mathrm{RPM}$ the error reached to $1.705 \mathrm{~mm}$.

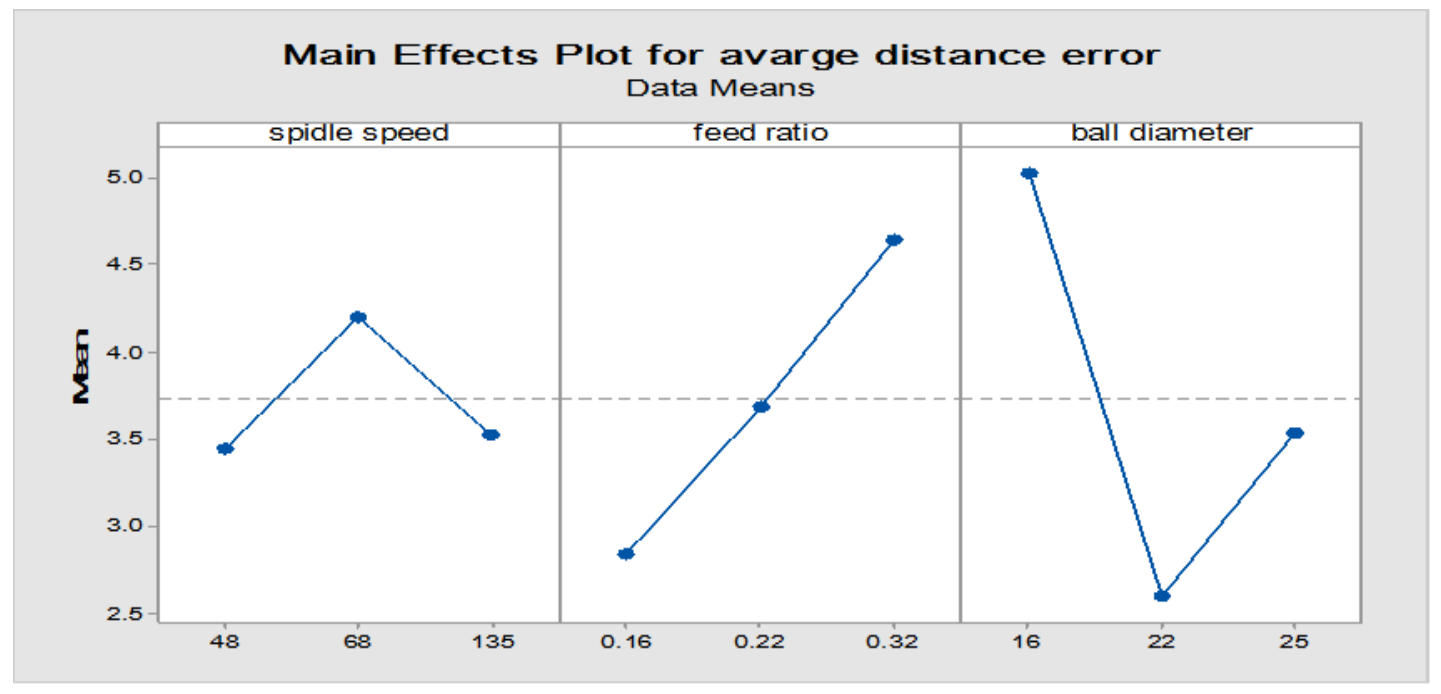

Figure 4: Schematic shows the main effect of parameters on average error.

Table 10: $\quad$ The percentage effect of each parameter on the dimensional error of the triangular spun part.

\begin{tabular}{c|cc}
\hline PARAMETER & PERCENTAGE EFFECT & RANK \\
\hline SPINDLE SPEED SS & $3.71 \%$ & 3 \\
FEED RATIO & $17.58 \%$ & 2 \\
TOOL BALL DIAMETER & $32.43 \%$ & 1 \\
\hline
\end{tabular}

\section{Acknowledgements}

Special thanks to all the contributors from the staff of the Dept. of Production and Metallurgy Eng. /Univ. of technology /Baghdad. 
All authors contributed equally to this work.

\section{Funding}

This research received no specific grant from any funding agency in the public, commercial, or not-for-profit sectors.

Data availability statement

The data that support the findings of this study are available on request from the corresponding author.

\section{Conflicts of interest}

The authors declare that there is no conflict of interest.

\section{References}

[1] K. M. Younis, A. I. Mohammed, J. J. Shukur, Rubber Pad Sheet Metal Forming of Round Metal Blanks into Multi Shape Axisymmetric Cups by FEA and Experimental Methods, Eng. Technol. J., 37 (2019) $370-376$. https://doi.org/10.30684/etj.37.3C.11

[2] Z. Jia, W. F. Peng, Z. R. Han, Q. Xu, Numerical simulation and experiment study on hollow spinning process for square cross-section cone, Int. J. Adv. Manuf. Technol., 75 (2014) 1605-1612. https://doi.org/10.1007/s00170-014-6242-4

[3] Y. Sugita, H. Arai, Effect of pass-set shape on formability in synchronous multipass spinning, Procedia Eng., 81 (2014) 2373-2378. https://doi.org/10.1016/j.proeng.2014.10.336

[4] J. M. Russo, Ch. J. Cleaver, J. M. Allwooda, The influence of part asymmetry on the achievable forming height in multipass spinning, J. Mater. Process. Technol., 275 (2020) 116350. https://doi.org/10.1016/j.jmatprotec.2019.116350

[5] Z. Jia, Z. J. Fan, Z. R. Han, Study on die-less spinning of square section cone with fellets, Int. J. Adv. Manuf. Technol., 106 (2020) 5149-5157. https://doi.org/10.1007/s00170-020-05003-8

[6] M. Razumov, A. Grechukhin, A. Pykhtin, Determination of Shape Errors during Polygonal Turning of Polyhedrons with an Odd Number of Faces, in Conference on Industrial Engineering, ICIE 2016, South-West State University, 150 (2016) 844-848. https://doi.org/10.1016/j.proeng.2016.07.130

[7] B. A. Ahmed, S. K. Shather, W. K. Hamdan, Improve the Micro-hardness of Single Point Incremental Forming Product Using Magnetic Abrasive Finishing, Eng. Technol. J., 38 (2020) 1137-1142. https://doi.org/10.30684/etj.v38i8A.906

[8] A. S. Bedan, K. K. Mansor, K. K. Anwer, H. H. Kadhim, Design and Implementation of Asymmetric Extrusion Die Using Bezier Technique, in 3rd International Conference on Sustainable Engineering Techniques ( ICSET),IOP Conf.Series: Mater. Sci. Eng. 881 (2020). https://doi.org/10.1088/1757-899X/881/1/012052

[9] S. A. Hamood, V. N. Najm, Optimization of Plasma Cutting Parameters on Dimensional Accuracy and Machining Time for Low Carbon Steel, Eng. Technol. J., 38 (2020) 1160-1168. https://doi.org/10.30684/etj.v38i8A.1151 